\title{
Life Time Approach for Prediction Groundwater Depletion
}

\section{Mahmoud Moustafa*}

Department of Geology, Suez University, Egypt

\begin{abstract}
Current approaches to quantify groundwater depletion due to poor management are water balance and Satellite gravity approaches. However, Water balance technique includes uncertain estimation of its parameter such as Eva transpiration and runoff. Satellite gravity method consumes time and effort. This work proposes using parametric life time techniques in a novel way to predict groundwater saturated thickness depletion. One of the most important issues in the failure theory proposed is to determine the failure point (depletion case). The proposed technique uses depth of water as the net result of recharge/discharge process in the aquifer, to calculate remaining saturated thickness resulted from the applied pumping rates in an area to evaluate the depletion. The two parameters Weibull function and Bayes analysis used to model and analyze the collected data. An illustrative example of the proposed methodology was carried out in a nonrenewable aquifer, no recharge; consequently the continuous decline in water depth is the main criterion to estimate the depletion. The value of the proposed approach is to predict the probable effect of the currently applied pumping rates on the saturated thickness with time based on the obtained remaining saturated thickness data especially on nonrenewable system. The limitation of the suggested approach is that it assumes the applied management practices are constant during the prediction period. Moreover, there is no major climate change. With further studies and applications the suggested method could be promising in prediction in different aspects of hydrology field.
\end{abstract}

Keywords: Depletion; Groundwater; Lifetime approach; Prediction

\section{Introduction}

\section{Groundwater depletion}

Groundwater depletion is the continuous reduction of groundwater storage volume. The reduction in groundwater storage is due to groundwater abstraction exceeds aquifer recharge. So that groundwater aquifer can't sustain development activities for long term. Groundwater depletion represents a great challenge, especially in nonrenewable aquifers such as Nubian Sandstone aquifer in the Western desert, Egypt. Many hydrogeological studies e.g. ULF and Heinl [1] indicate that the aquifer is a nonrenewable resource (no recharge). This aquifer suffers from continuous water levels decline as a result of over pumping due to Oasis development $[2,3]$. The wells in this area were flowing. However, after nearly 50 years the head drop in some places to 60 meters [3]. The thickness of the aquifer in the Oasis average 400 meters $[4,5]$.

\section{Quantifying groundwater depletion}

Currently groundwater depletion mostly quantified with Satellite gravity and water balance approaches. In Satellite gravity approach, the Earth's gravity field is the result of the mass distribution in the Earth system. Mass redistribution in the Earth system changes the gravity field. Satellite gravity has the ability of measuring groundwater water storage change and ocean mass variations [6]. Famiglietti [7] used satellite gravity to estimate groundwater depletion.

In water balance approach, depletion can be quantified by estimating groundwater water storage change. Water storage change is the difference between system recharge (input) and system abstraction or seepage (output). If system abstraction/loss more than system recharge depletion occur. Depletion varies as pumping change over time. Water storage change can be quantified using simple water balance following equation:

$$
\begin{aligned}
& \mathrm{P}=\mathrm{ET}+\mathrm{Qs}+\mathrm{Qn}+\Delta \mathrm{S} \\
& \text { P: Precipitation } \\
& \text { ET: Evatranspiration } \\
& \text { Qs: Surface run off }
\end{aligned}
$$

Qn: Net inflow/out flow to the groundwater system

\section{$\Delta \mathrm{S}$ : Water storage change}

McGuire et al. [8], integrate measurements of changes in groundwater levels and storage activity to estimate depletion. Kalbfleisch [9] used water balance and pumping test for depletion quantification. Faunt et al. [10] used deterministic calibrated groundwater flow models to quantify groundwater depletion.

\section{Life time approach}

Survival or life time data analysis is used when it is desirable to study the time elapsed from some particular starting point to the occurrence of an event; this time is called survival time or life time [11]. Survival analysis is used in many fields of study, e.g. time to relapse of cancer or duration of strikes in economics [12]. The data that measure the length of time until the occurrence of an event are called life time data. The analysis consisted of following the subject till death. Since time is a common measure of life, life data points are often called "times-to-failure".

\section{Types of life data}

I) Complete data, the exact time-to-failure for the unit is known (e.g. The tested unit failed at $\mathrm{x}$ hours of operation).

II) Right censored data, the tested unit still work for an unknown period of time (e.g. the tested unit was still work after and during the test time) i.e. no failure happened till the end of test time

III) Interval censored data, the exact time-to-failure is unknown, but it falls within a known time range. For example, the tested unit failed between $\mathrm{x}$ hours and $\mathrm{y}$ hours (interval censored).

*Corresponding author: Mahmoud Moustafa, Department of Geology, Suez University, Egypt, Tel: 01023620044; E-mail: mahmoud.moustafa@yahoo.co.uk

Received July 09, 2015; Accepted August 11, 2015; Published August 21, 2015

Citation: Moustafa M (2015) Life Time Approach for Prediction Groundwater Depletion. J Civil Environ Eng 5: 184. doi:10.4172/2165-784X.1000184

Copyright: (c) 2015 Moustafa M. This is an open-access article distributed under the terms of the Creative Commons Attribution License, which permits unrestricted use, distribution, and reproduction in any medium, provided the original author and source are credited. 
This technique of censoring enabled researchers to analyze incomplete data due to delayed entry or withdrawal from the test [13]. This type of analysis is widely used in reliability engineering studies. Reliability engineering assessment is based on the results of testing from labs and data pertaining to the performance results of the product in the field. The data produced by these sources are utilized to measure the reliability of the products being produced.

In life data analysis, it is possible to make predictions about the life of the tested unit or product by fitting a statistical distribution to life data from a representative sample of the unit under study. The parameterized distribution of the data set can then be used to estimate life characteristics of the product such as reliability or probability of failure at a specific time and the failure rate can be estimated. Life data analysis requires the following:

- Gather life data for the tested unit or object under study.

- Select a lifetime distribution (e.g. Weibull distribution function) that will fit the data.

- Model the failure time or life of the tested unit.

- Generate plots that estimate the life characteristics.

The method of analysis must take the censoring into account and use the censored observations as well as the uncensored observations. The percentiles of population that have been failed calculated by the following equation

$$
X p=\beta[\ln (1-p)]^{1 /} \eta^{\prime}
$$

Where $\beta$ and $\eta$ are scale and shape parameters respectively, of Weibull distribution function.

\section{$\mathrm{X}$ is a variable}

\section{$\mathrm{P}$ is the probability}

The survival probability function is the probability that a unit survives beyond time $(\mathrm{t})$ and is calculated by

$$
\mathrm{R}(\mathrm{t})=1-\mathrm{f}(\mathrm{t})
$$

Where $f(t)$ is the probability distribution function of a given distribution, the hazard rate is defined as the probability per time unit that a case will fail in a given time interval. It provides a measure of the likelihood of failure as a function of how long a unit has lasted. The failure rate at a particular time $(\mathrm{t})$ is calculated by;

$$
\mathrm{h}(\mathrm{t})=\mathrm{f}(\mathrm{t}) / 1-\mathrm{F}(\mathrm{t})
$$

Where $\mathrm{f}(\mathrm{t})$ is the PDF (probability distribution function) of the Weibull distribution [14]:

$$
f(t)=\beta / \eta(t / \eta)^{\beta-1} e^{-((t / \eta) \beta}
$$

$\beta=$ shape parameter, $\eta=$ scale parameter

$\mathrm{F}(\mathrm{t})$ is the CDF of the given distribution.

$$
\mathrm{CDF}=\mathrm{F}(\mathrm{t})=1-\mathrm{e}^{-(\mathrm{t} / \beta) \eta}
$$

CDF (Cumulative Distribution Function) is the probability that a random variable has a value less than or equal to $\mathrm{x}$. The hazard rate was estimated according to the following equation [14]:

Failure rate $=\eta / \beta(\mathrm{t} / \beta)^{\eta-1}$

\section{Main characteristic in applying life time approach}

An important characteristic in this technique is to determine the failure point. Based on an estimated failure point the collected data classified to censored (failure not happened) or non-censored (exact failure happened). This work explores parametric life time analysis to estimate the probable time for aquifer saturated thickness depletion based on the predefined failure or depletion point, using depth to water as a net result of recharge/discharge process. In this study, life time analysis technique is explored to estimate the lifetime of the remaining saturated thickness of groundwater aquifer.

\section{Methods}

The suggested approach uses depth of water as the net result of the discharge/recharge process in the aquifer. In this case study, the aquifer has no recharge (nonrenewable aquifer). According to life time analysis, the tested unit in this study is the saturated thickness of the groundwater aquifer. This tested unit (saturated thickness) subjected to over-pumping with time. An important point in the lifetime analysis is to determine the failure point or event (when failure happens). In this work if the original saturated thickness $(400 \mathrm{~m})$ attained $1 / 4$ of its original value considered failure point or depletion event. In a life time analysis if the tested unit, saturated ND thickness, not failed (i.e. Not attained $1 / 4$ of original saturated thickness) till the end of test time (monitoring period) the saturated thickness value called right censored value (i.e. No failure happened till the end of monitoring period) and this value coded ( 0 ) for statistical analysis. If saturated thickness attained $1 / 4$ of its original thickness during monitoring period, it means depletion happened and this value coded (1).

\section{Data collection}

Depth of water data were collected from 1962 till 2009 years in (Garmashin 3) monitoring well in a Nubian Sandstone aquifer, Kharga Oasis, Western Desert, Egypt (Figure 1). The remaining saturated thickness of the aquifer was calculated during monitoring period Table (1). Different distribution functions were used to determine the best fit function to failure time data (Figures $2 \mathrm{a}$ and $2 \mathrm{~b}$ ). In this analysis Weibull parametric distribution analysis used in estimating failure time characteristics with no failure. The two Weibull parametric distribution coefficients ( $\beta$ shape parameter and $\eta$ scale parameter) used to estimate the percentiles of failure time using the maximum

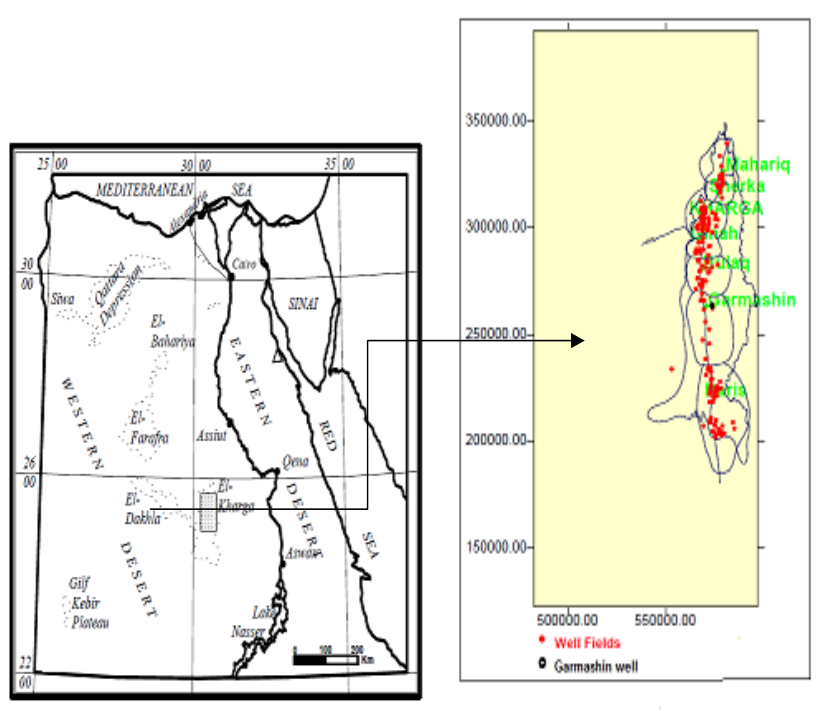

Figure 1: Location study area (Kharga Oasis, Western Desert, Egypt). 




Figure 2: Flow chart for the proposed methodology.

likelihood estimation method (MLE). The percentiles were calculated using the following equation:

$\mathrm{Xp}=\beta[\ln (1-\mathrm{p})]^{1 /} \eta^{\prime} \quad[14]$. Because no failure point recorded Bayes analysis used to give the lower or upper $95 \%$ confidence of the prediction [15]. Flow chart for the proposed procedure outlined in Figure (2).

Depletion thickness assumed to be $1 / 4$ the original saturated thickness

\section{Results}

The data collected revealed that the saturated thickness of the aquifer not reached to failure point, i.e. depletion case, (thickness did not attain $1 / 4$ of its original value). This means that all the data is right censored (no failure, i.e. depletion happened till the end of monitoring period or testing period) (Table 1). From distribution functions fitted to the data (Figures $3 \mathrm{a}$ and $3 \mathrm{~b}$ ), Weibull function chosen for analysis the data for two reasons. Firstly, it is the most function that fits the data. This is appeared from obtained correlation coefficient. The second reason is Weibull and Exponential functions only can be used to analyze lifetime data with no failure case/event. Moreover, Weibull can be easily fit the data more than the Exponential function. Other functions, although they have a high correlation coefficient it can't analyze data with no failure, it needs at least one failure point.

\section{Probability of saturated thickness depletion}

The cumulative probability failure (no depletion) with time (Figure 4) suggested that after 300 years probability of $80 \%$ of the saturated aquifer will be depleted with probability that total saturated thickness can be depleted after 400 years from start of exploitation in (1962). 95\% confidence upper bound estimated using Bayes analysis [15]

\section{Probability of survival (No depletion)}

The survival plot (Figure 5) only graphs the theoretical probabilities with time. Each plot point represents the proportion of units, saturated thickness that surviving (still saturated) not reached to the failure point ( $1 / 4$ of original saturated thickness). This graph suggests that only $25 \%$ of the saturated thickness will remain after 300 years of exploitation since 1962 with only lower bound 95\% confidence, because no failure point recorded during monitoring events [15].

\begin{tabular}{|c|c|c|c|}
\hline $\begin{array}{l}\text { Monitoring } \\
\text { Time }\end{array}$ & $\begin{array}{l}\text { Cumulative } \\
\text { Drawdown }\end{array}$ & $\begin{array}{c}\text { Remaining saturated } \\
\text { Thickness }\end{array}$ & $\begin{array}{l}\text { Right Censor value } \\
\text { (No failure till end of } \\
\text { monitoring time) }\end{array}$ \\
\hline 1962 & 0.1 & 399.9 & 0 \\
\hline 1963 & 0.2 & 399.8 & 0 \\
\hline 1964 & 0.33 & 399.67 & 0 \\
\hline 1965 & 0.4 & 399.6 & 0 \\
\hline 1966 & 0.5 & 399.5 & 0 \\
\hline 1967 & 0.6 & 399.4 & 0 \\
\hline 1968 & 0.7 & 399.3 & 0 \\
\hline 1969 & 0.8 & 399.2 & 0 \\
\hline 1970 & 0.9 & 399.1 & 0 \\
\hline 1971 & 1 & 399 & 0 \\
\hline 1972 & 1.3 & 398.7 & 0 \\
\hline 1973 & 1.2 & 398.8 & 0 \\
\hline 1974 & 1.5 & 398.5 & 0 \\
\hline 1975 & 1.7 & 398.3 & 0 \\
\hline 1976 & 1.8 & 398.2 & 0 \\
\hline 1977 & 1.9 & 398.1 & 0 \\
\hline 1978 & 2.1 & 397.9 & 0 \\
\hline 1979 & 2.5 & 397.5 & 0 \\
\hline 1980 & 2.8 & 397.2 & 0 \\
\hline 1981 & 2.9 & 397.1 & 0 \\
\hline 1982 & 3.2 & 396.8 & 0 \\
\hline 1983 & 3.5 & 396.5 & 0 \\
\hline 1984 & 3.8 & 396.2 & 0 \\
\hline 1985 & 4.1 & 395.9 & 0 \\
\hline 1986 & 4.5 & 395.5 & 0 \\
\hline 1987 & 4.72 & 395.28 & 0 \\
\hline 1988 & 6.69 & 393.31 & 0 \\
\hline 1989 & 8.44 & 391.56 & 0 \\
\hline 1990 & 10.71 & 389.29 & 0 \\
\hline 1991 & 12.17 & 387.83 & 0 \\
\hline 1992 & 13.57 & 386.43 & 0 \\
\hline 1993 & 14.5 & 385.5 & 0 \\
\hline 2000 & 24 & 376 & 0 \\
\hline 2001 & 26 & 374 & 0 \\
\hline 2002 & 29 & 371 & 0 \\
\hline 2003 & 34 & 366 & 0 \\
\hline 2004 & 36 & 364 & 0 \\
\hline 2005 & 40 & 360 & 0 \\
\hline 2006 & 45 & 355 & 0 \\
\hline 2007 & 50 & 350 & 0 \\
\hline 2008 & 55 & 345 & 0 \\
\hline 2009 & 60 & 340 & 0 \\
\hline
\end{tabular}

Table 1: life time data used in the analysis (First and last column). 

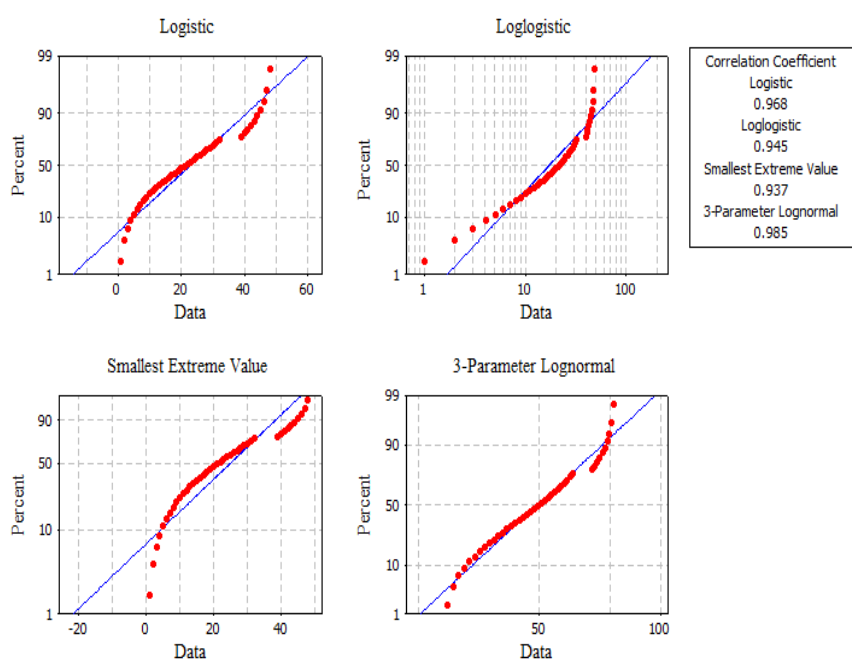

Figure 3a: Different probability distribution function to failure time data.
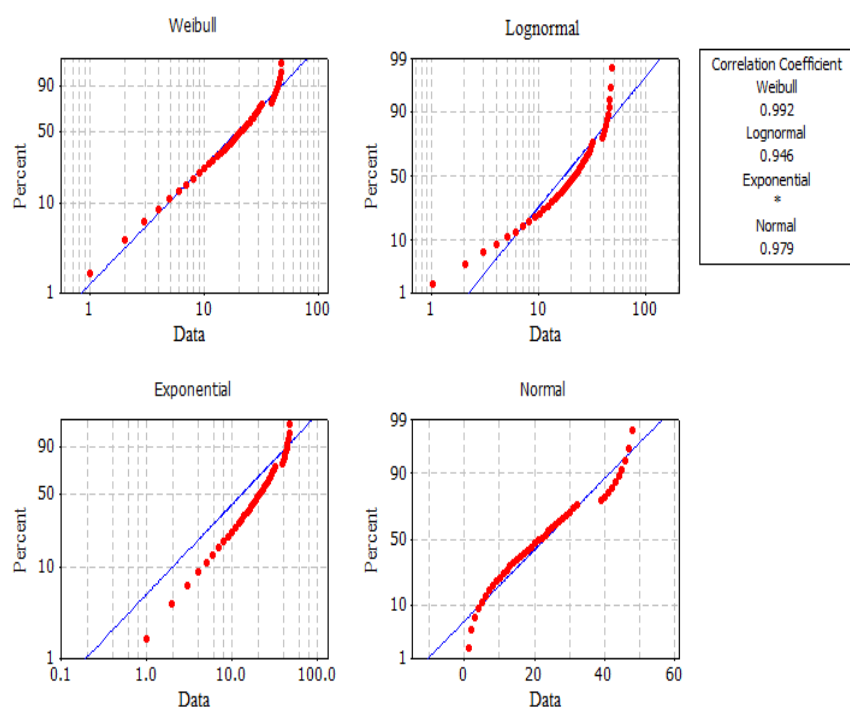

Figure 3b: Different probability distribution function to failure time data.

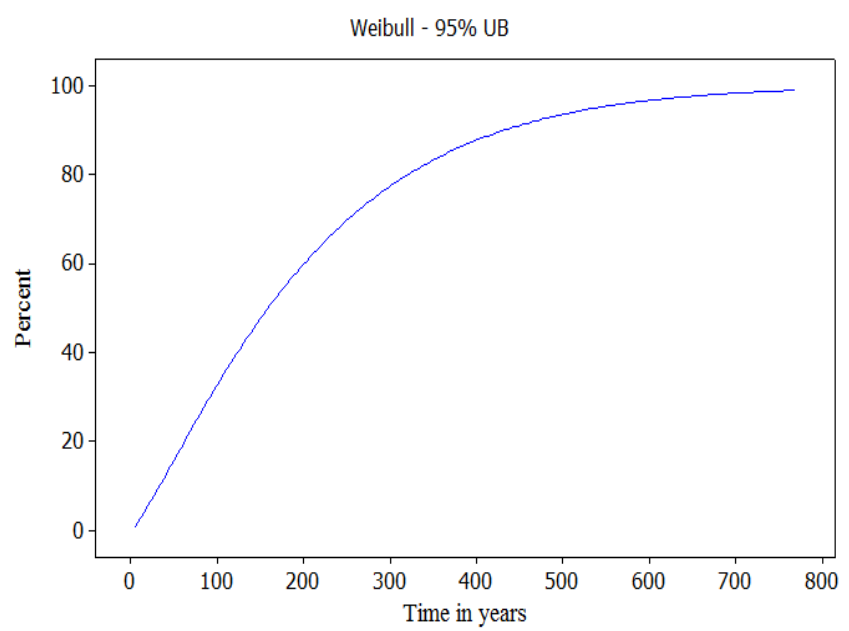

Figure 4: Cumulative probability failure of saturated thickness depletion.

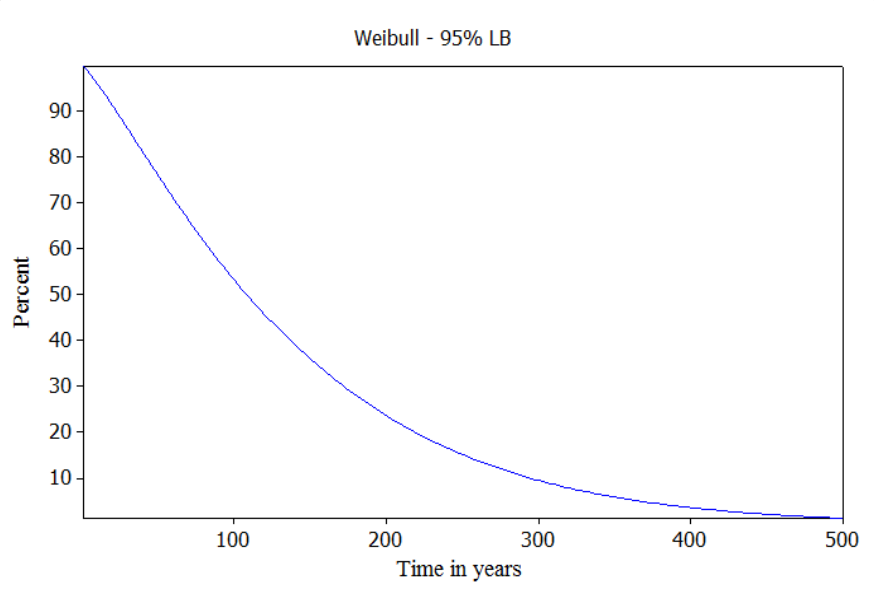

Figure 5: Probability of survival of aquifer saturated thickness.

\section{Discussions}

The above predicted results for probability depletion of saturated thickness using failure theory are based on the result of pumping rates in the area from 1962 till 2009. Which is reflected by the obtained depth to water? The predicted results using this approach are based on the assumption that pumping policy or rates in the area are constant during prediction time. In addition the suggested life time approach assumes no climate change so no major rainfall recharge to the aquifer, which affect the resulting depth to water and consequently the remaining saturated thickness. The failure theory approach could use to examine the probable effect of currently applied management practices on the saturated thickness in the future. This approach may be somewhat like the flow model [16] which used to predict the effect of the management plane in an area on the depth to water in the future. However, the proposed failure theory approach uses the results of the applied management plans to predict the depletion probability of the saturated thickness with time. Barber [2] predicts the depth of water to be around 80 meters in 2050 year (nearly after 90 years since 1962) at the study site (garmashin). It means 320 meters of the saturated thickness still remaining, around 75 or $80 \%$ from the original saturated thickness still not depleted. This may agree with the predicted survival graph (Figure 5).

\section{Conclusion}

This life time approach could predict the remaining saturated thickness under current pumping rates.

\section{References}

1. ULF T, Heinl M (2002) Groundwater resources of the Nubian aquifer system NE Africa. Report for Technical University of Berlin, Berlin.

2. Barber W (1977) Groundwater pilot scheme, new valley. Egypt. Report for the Government of Egypt. A united nation development program. Food and agriculture organization of the united nation.

3. Soliman S (2013) Mitigation of Excessive Drawdowns via Rotational Groundwater Withdrawal (Case study: El Kharga Oases, Egypt). New York Sci J 6.

4. Ezzat A (1976) Exploitation of groundwater in El Wadi-El Gedid project area (New Valley). Ministry of Agriculture and Land Reclamation, Cairo, Egypt.

5. Himida IH (1968) Quantitative study of the artesian water exploitation resources in Kharga and Dakhla Oases, Western Desert of Egypt.

6. Rodell M, Velicogna I, Famiglietti JS (2009) Satellite based estimates of groundwater depletion in India. Nature 460: 999-1002.

7. Famiglietti JS, Lo M, Ho SL, Bethune J, Anderson KJ, et al. (2011) Satellites 
measure recent rates of groundwater depletion in California's Central Valley. Geophys Res Lett 38: L03403.

8. McGuire VL, Johnson MR, Schieffer RL, Stanton JS, Sebree SK, et al. (2003) Water in storage and approaches to groundwater management, High Plains Aquifer, 2000. US Geol Surv Circ 1243: 51.

9. Kalbfleisch JD, Prentice RL (1980) The statistical analysis of failure time data.

10. Faunt CC, Hanson RT, Belitz K, Schmid W, Predmore SP, et al. (2009) Numerical model of the hydrologic landscape and groundwater flow in California's Central Valley. In: Faunt CC (ed.) Groundwater Availability of the Central Valley Aquifer, California. US Geol Surv Prof Pap 1766: 121-212.

11. Kececioglu D (1991) Reliability Engineering Handbook. Prentice Hall, Inc., Englewood Cliffs, New Jersey, USA.
12. Abernethy RB (2000) The new Weibull handbook: Reliability and statistical analysis for predicting life, safety, survivability, risk and warning claims substantiation and accelerated testing, using Weibull, Log normal, crowAMSAA, probit, and Kaplan-Meier models (5thedn.) North Palm Beach.

13. Mahesh P, Cheung YB, Machin D (1996) Survival analysis: a practical approach. John Wiley and Sons, UK.

14. Lawless JF (1982) Statistical models and methods for lifetime data. John Wiley and Sons, New York.

15. Wayne N (1985) Weibull Analysis of Reliability Data with Few or No Failures J Quality Tech 17.

16. McDonald MG, Harbaugh AW (1988) A Modular Three-Dimensional FiniteDifference Ground-Water Flow Model. Scientific Publications Co., pp. 1-586. 